\title{
Culturally Engaging Courses and Campuses for LGBQ+ Issues
}

\author{
Allison BrckaLorenz ${ }^{\mathrm{a}}$ \\ Antonio Duran ${ }^{\mathrm{b}}$ \\ Heather Haeger ${ }^{\mathrm{c}}$ \\ Ulises Duenaz ${ }^{\mathrm{c}}$
}

\author{
a. Indiana University Bloomington \\ b. Auburn University \\ c. California State University Monterey Bay
}

Paper presented at the Annual Meeting for the Association for the Study of Higher Education November 2019 


\begin{abstract}
Current literature underscores the need to address unwelcoming campus climates for LGBQ+ students both in and outside of the classroom by taking a critical look at the practices adopted at the institution. Using a large-scale, multi-institution quantitative and qualitative data set, this study examined student perceptions of the inclusion of LGBQ+ issues in curricula and how this relates to other forms of engagement. We found differences in student perceptions by major and sexuality, and that relationships between engagement and LGBQ+ curricular inclusion are strong for LGBQ+ and non-LGBQ+ students. Quotes from students highlight the disconnect felt between coursework and discussions of sexuality, as well as the great importance of creating inclusive spaces for the LGBQ+ community.
\end{abstract}




\section{Culturally Engaging Courses and Campuses for LGBQ+ Issues}

Y'all are not here for us. Step it up."

-A queer identifying student's write-in response

Within the field of higher education, scholars emphasize the reality that the experience of campus climate and culture varies by students' backgrounds and social identities (see Museus, 2014). What this body of research showcases is that students' perceptions of how accepting and welcoming their campus environments are differ based on a person's social location, especially relevant for collegians from historically marginalized identities (e.g., Museus, 2014; Museus, Yi, \& Saelua, 2018; Tyson, 2019). For example, researchers highlight the negative campus climates that individuals from the $\mathrm{LGBQ}+{ }^{1}$ community encounter at their higher education institutions (e.g., Evans, Nagoshi, Nagoshi, Wheeler, \& Henderson, 2017; Garvey, Sanders, \& Flint, 2017; Greathouse et al., 2018; Woodford \& Kulick, 2015). This area of scholarship underscores the need to address unwelcoming campus climates for LGBQ+ students both in and outside of the classroom by taking a critical look at the practices adopted at the institution.

Connected to this research, scholars started to look at structures and initiatives within university environments that shape students' perceptions of campus, such as policies, clubs, and course offerings (Pitcher, Camacho, Renn, \& Woodford, 2018; Woodford, Kulick, Garvey, Sinco, \& Hong, 2018). One area of importance is how open people are to discussing LGBQ+ issues in the classroom, an often-ignored conversation. In particular, not engaging in conversations about sexuality in classes and on campuses can have significant effects on how

\footnotetext{
${ }^{1}$ In this manuscript, we use the acronym LGBQ+ to represent those who identified as lesbian, gay, bisexual, queer, questioning, and with other sexual minority identities - language that aligned with the 2017 administration of the National Survey of Student Engagement (NSSE). However, when referring to scholarship, we mirror the language employed by the authors (e.g., queer-spectrum, LGBTQ, etc.).
} 
engaged LGBQ+ students are at their university (Brockenbrough, 2018; Guerrero, Shahnazarian \& Brown, 2017), as well as how they view their campus climate. Because of this erasure of LGBQ+ issues, higher education professionals also lack the knowledge of how including LGBQ+ topics in curricula can impact students across different sexualities, including those who identify as heterosexual.

Thus, the purpose of this research was to examine how students differed in their perceptions of how open their institution is to integrating LGBQ+ topics in the classroom when considering sexuality and major. Using a blend of quantitative analyses while also including students' responses to a qualitative open-ended survey question, this study provides a nuanced and critical understanding of how individuals both within and outside of the LGBQ+ community vary in their perceptions and how this affects other forms of engagement at the institution. Aligning with the vision of the will to reimagine the study of higher education, this study challenges the belief that only students who identify within the LGBQ+ community benefit from the integration of LGBQ+ topics across campus and in curricula. The questions that guided this inquiry were as follows:

1. How do perceptions of the curricular inclusion of LGBQ+ issues differ by students' sexual orientation and major?

2. How do perceptions of the curricular inclusion of LGBQ+ issues relate to other forms of engagement for both LGBQ+ and non-LGBQ+ students?

In reimagining practice in student affairs, as well as academic affairs, the results from this study have the potential to help educators advocate for the incorporation of these subject matters in classrooms and at institutions broadly. Consequently, institutional agents will be better prepared 
to support the LGBQ+ community on their campuses, which in turn can affect these individuals' experiences of their collegiate culture.

\section{Conceptual Framework}

In understanding diversity and inclusivity for LGBQ+ students, we approached this topic by examining two parts of a three-tiered lens (BrckaLorenz et al., 2019). Although not the focus of this study, the first tier considers the foundation of an inclusive environment to be representation. Increasing compositional diversity is beneficial to the broader campus community in terms of recruitment, retention, and academic success (Astin, 1993; Brown, 2006; Cole, 2007; Cole \& Espinoza, 2008; Tinto, 2006). Pike and Kuh (2006) demonstrated that as compositional diversity increases, so do diverse interactions among peers and perceptions of more supportive campus environments. In this study, we examine inclusivity in coursework within different disciplines and look at a broader examination of perceptions of the supportiveness of the campus culture (the other two tiers). See Figure 1.

In the second level of the model, we explore the degree to which coursework fosters an inclusive environment. Scholars associate culturally relevant pedagogy, which incorporates students' diverse backgrounds and cultures into the classroom, with a number of positive student outcomes (Aronson \& Laughter, 2016; Ladson-Billings, 2006; Marquez Kiyama \& Rios-Aguilar, 2017); however, this research largely ignores how courses can be relevant and engaging for LGBQ+ students (Brockenbrough, 2018; Guerrero et al., 2017). Heterosexist norms and policies may also discourage instructors from engaging in culturally relevant content and discussions around sexuality and identity in the same way they do with more widely accepted aspects of identity like race (Rhodes \& Coda, 2017). We measure how culturally engaging courses are in 
terms of how much students engage in discussions about LGBQ+ issues and how comfortable students feel brining up these issues in and out of class.

In the third level of our model, we conceptualize a supportive campus environment for LGBQ+ students as an environment that creates a sense of community with other LGBQ+ students, fosters discussion of LGBQ+ issues, and contributes to students' understanding of themselves and their identity. Interactions in and out of the classroom along with institutional policies communicate to students the level of institutional commitment to diversity and inclusion (Pike \& Kuh, 2006). Noted in previous sections, a significant body of research has demonstrated that LGBQ+ students still experience an unwelcoming and heterosexist environment on college campuses - even if these climates are improving over time (Garvey et al., 2017).

\section{Literature Review}

In order to inform this study's design, we reviewed scholarship relevant to our topic of interest: the impact of curricular inclusion of LGBQ+ issues. Namely, guided by the BrckaLorenz, Haeger, and Priddie's (2019) nested model for diversity and inclusion (see Figure 1), we found it important to survey the literature relevant to the two tiers that were most pertinent to the research questions. Consequently, we first examine the existing scholarship on inclusive curricular environments with a specific focus on LGBQ+ students, before then exploring the literature on the ways that LGBQ+ collegians experience their campus environments.

\section{Inclusive Classroom Environments and LGBQ+ Students}

Recognized in BrckaLorenz et al.'s (2019) nested model, culturally engaging courses are key to promoting matters of diversity and inclusion on college campuses. Noted previously, culturally responsive pedagogical approaches can substantially shape the experiences of minoritized individuals (Aronson \& Laughter, 2016; Ladson-Billings, 2006; Marquez Kiyama \& 
Rios-Aguilar, 2017). Yet, the absence of this kind of pedagogy can conversely have negative impacts on these populations, including those who are part of the LGBQ+ community (Brockenbrough, 2016; Guerrero et al., 2017). To illuminate this point, we highlight the research on how curricular spaces target the inclusion of LGBQ+ individuals and issues.

Specifically, a growing body of research named the ways that LGBQ+ individuals experience curricular spaces (e.g., Bilimoria \& Stewart, 2009; Brown, Clarke, Gortmaker, \& Robinson-Keilig, 2004; Hughes, 2018; Patridge, Barthelemy, \& Rankin, 2014; Sevecke et al., 2015). For example, reviews of literature pertaining to LGBQ+ students regularly reveal the differences that exist across academic disciplines concerning LGBQ+ inclusion (Linley \& Nguyen, 2015; Rankin, Garvey, \& Duran, 2019). Studies showcase that LGBQ+ individuals frequently perceive STEM disciplines as more likely to overlook the relevance of sexuality and to render LGBQ+ issues invisible (Bilimoria \& Stewart, 2009; Hughes, 2017; Patridge et al., 2014). As a result, it is unsurprising that studies such as Hughes' (2018) revealed that sexual minority individuals were less likely to remain in STEM disciplines compared to their heterosexual peers. Conversely, disciplines in the social sciences and humanities are more accepting of LGBQ+ identities (Brown et al., 2004; Linley \& Nguyen, 2015; Rankin et al., 2019). Important to acknowledge is that matters of LGBQ+ inclusion can have positive effects on students' lives and collegiate experiences, a finding that can apply to individuals across sexualities.

For example, Sevecke et al.'s (2015) study on undergraduate coursework pertaining to gay and lesbian issues found various beneficial impacts. Sevecke et al. noted that exposing undergraduate students to curricula with gay and lesbian content led to individuals feeling more confident in interactions with gay or lesbian roommates. Moreover, the inclusion of gay and 
lesbian issues also led to a sense of preparedness to navigate gay and lesbian issues in the workplace. Though relevant to those of all sexualities, other studies addressed the impacts of such inclusion on LGBQ+ students specifically. Of note, offering LGBTQ courses can have a beneficial impact on LGBTQ students' well-being, a finding from Woodford et al.'s (2018) study on LGBTQ policies and resources that contribute to psychological health for this population. It is evident that how often (or not) faculty integrate LGBQ+ issues in their classroom and in the broader curriculum shapes students' experiences at their institution.

Yet, the classroom represents only one space within a larger campus environment that shapes a person's view of the institutional climate. In fact, Vaccaro (2012) used Ackelsberg, Hart, Miller, Queeny, and Van Dyne's (2009) language of microclimates to suggest that LGBT individuals can experience the macro-level institutional space differently than more micro-level environments on campus. Nevertheless, these two (the microclimate and overall campus climate) are inextricably related. Namely, Garvey et al.'s (2017) investigation of generational differences of campus climate among LGBTQ undergraduates named academic experiences as one important variable connected to how students perceive their institutions. Conversely, studies also show that positive perceptions of campus climate also predict academic success for queerspectrum collegians (Garvey, Squire, Stachler, \& Rankin, 2018). For this reason, we see it necessary to also review the literature on LGBQ+ students and the broader campus environment.

\section{LGBQ+ Students and (Un)supportive Campus Environments}

Like perceptions of curricular spaces, scholars documented the troubling realities that LGBQ+ students face as it relates to issues of institutional climates (Evans et al., 2017; Garvey et al., 2017; Greathouse et al., 2018; Woodford \& Kulick, 2015). Though recent literature reveals a progressively improving campus climate for LGBQ+ individuals (Garvey et al., 2017; Rankin et 
al., 2019), research still underscores that these students encounter heterosexist environments at higher education institutions (Blumenfeld, Weber, \& Rankin, 2016; Woodford et al., 2018; Woodford, Kulick, Sinco, \& Hong, 2014). Thus, we review the scholarship that centers on what contributes to students' views of their campus climate before then examining research showcasing the effects that result from these perceptions.

One area of campus climate research investigates what contributes to students' positive (or negative) perceptions of these environments. As it relates to the academic sphere, researchers communicated that one significant experience that leads to positive views of the campus climate involves knowing faculty/staff who are out with their sexuality (Garvey et al., 2017). For collegians who identify as sexual minorities, seeing others who have negotiated their identities in the academy can shape the belief that their institutional environment can be accepting of those who are part of the LGBQ+ community. Outside of curricular factors, scholars noted the presence of resources for the LGBQ+ community (e.g., student organizations and resource centers) as one important variable that relates to matters of student success, climate, and wellbeing (Pitcher et al., 2018; Woodford et al., 2018). These influences (i.e., knowing out faculty/staff, as well as having institutional resources) are significant because they affect how colleges or universities position LGBQ+ issues, including how often they are discussed - a central variable of interest in this study.

Of note, scholars emphasize that how LGBQ+ collegians experience their campus environments and climates is related to several student outcomes that inevitably impact engagement (Garvey, Mobley, et al., 2018; Garvey, Squire, et al., 2018; Woodford et al., 2014; Woodford \& Kulick, 2015; Woodford, Kulick, \& Atteberry, 2015). In fact, Blumenfeld et al.'s (2016) research on LGBT people (i.e., students, staff, and faculty) suggested that campus climate 
affects how likely these individuals are to persist in higher education, which relates to Woodford and Kulick's (2015) findings that campus climate impacts sexual minority students' academic and social integration. On a more intrapersonal level, campus climates also have the potential to impact a students' well-being and identity management. For example, Garvey, Mobley, et al.'s (2018) study on queer and trans students of color showcased that campus climate perceptions had a strong relationship with how comfortable a person was being 'out,' or disclosing their sexuality, at their institution. Additionally, numerous studies drew connections between heterosexist campus climates and LGBQ+ students' overall psychological well-being and health (Woodford et al., 2015; Woodford, Kulick, et al., 2018). Reasonably, these outcomes (e.g., academic integration/success, outness, and psychological well-being) all connect to matters of engagement for LGBQ+ students. For this reason, this scholarship set a necessary foundation for this present study.

\section{Methods}

The data from this study come from the 2017 administration of the National Survey of Student Engagement (NSSE). NSSE annually collects information from hundreds of four-year colleges and universities about first-year and senior students' participation in programs that institutions provide for their learning and personal development. More specifically, NSSE asks students about their participation in curricular and co-curricular activities, their experiences in their courses, interactions with others, and perceptions of campus support. A subset of 30 participating NSSE institutions received an additional item set asking students about LGBQ+ issues at their institution. This study focuses on the responses of over 13,000 students who responded to items in this additional set as well as questions about their sexual orientation and their major or expected major. Of the students in this study $(n=13,421)$, slightly over half $(58 \%)$ 
were seniors. Over one in ten (12\%) students identified as LGBQ+ with the largest proportions of students majoring in Business (17\%), Social Sciences (14\%), and Arts \& Humanities (13\%). See more details about respondents and the institutions they attended in Table 1.

\section{Respondents}

We included students in this study if they responded to the questions about their sexual orientation and major or expected major as well as to a series of items in the additional LGBQ+ issues question set. For sexual orientation, students were asked to select which from the following best describes their sexual orientation: Straight (heterosexual); Bisexual; Gay; Lesbian; Queer; Questioning or unsure; Another sexual orientation, please specify; and I prefer not to respond. We omitted students who chose I prefer not to respond for sexual orientation from this study. For major or expected major, students indicated their major by typing in a response to the prompt "Please enter your major or expected major." If their write-in response did not match one from a list of common majors, students indicated their major by selecting from a list ${ }^{2}$. When students indicated two majors, we only used their first in this study.

\section{Measures}

The additional LGBQ+ items used in this study asked students how often are LGBQ+ issues discussed in their courses, how much has their experience at their institution contributed to their understanding of LGBQ+ issues, and how comfortable would they feel bringing up LGBQ+ issues in course discussions. Additionally, they reported how often they have had discussions with LGBQ+ people or about LGBQ+ issues outside of class. We averaged these items together to create a single scale measure. Find the full text of items and measure details in Table 2.

\footnotetext{
${ }^{2}$ More details about how NSSE collapsed these majors into the eleven categories studied here see http://nsse.indiana.edu/pdf/NSSE\%2010\%20Major\%20Categories.pdf.
} 
Although not central to the study, student responses to the open-ended question "Please share any reflections or experiences regarding LGBQ+ issues at your institution" were included when appropriate to give context to our quantitative findings.

We included several measures of engagement, referred to as NSSE Engagement Indicators ${ }^{3}$, as outcomes for this study. Higher-Order Learning asks how much students' coursework emphasizes challenging cognitive tasks such as application, analysis, and synthesis. Reflective \& Integrative Learning asks how often students make connections between their learning and the world around them and consider issues and ideas from others' perspectives. Collaborative Learning asks how often students work on group projects, ask peers for help, and explain difficult material to others. Discussions with Diverse Others asks how often students interact with and learn from others with different backgrounds and life experiences. StudentFaculty Interaction asks how often students interact with their faculty outside of courses. Quality of Interactions asks students about supportive relationships with other students, advisors, faculty, and staff. Supportive Environment asks how much a student's institution emphasizes support across a variety of domains including cognitive, social, and physical. We additionally include a NSSE measure, Perceived Gains, that asks students how much their institution has contributed to their knowledge, skills, and personal development in general education, practical competence, and personal and social development.

\section{Analyses}

To answer our first question about how perceptions of LGBQ+ inclusion differ by students' sexual orientation and major, using $t$-tests, ANOVAs, and Cohen's $d$ effect sizes, we examined differences on our LGBQ+ inclusion measure to see how these perceptions differ by

\footnotetext{
${ }^{3}$ Find more details about these measures and their component items at nsse.indiana.edu.
} 
students' sexual orientation (collapsed into an LGBQ+/non-LGBQ+ binary) and major or expected major. We ran all analyses separately for first years (FY) and seniors (SR), and we used Rocconi and Gonyea's (2018) recommendation ${ }^{4}$ for interpreting effect sizes using NSSE data. To answer our second question about how perceptions of LGBQ+ inclusion relate to other forms of effective educational practice for both LGBQ+ and non-LGBQ+ students, we used a series of regression equations to look at the relationship between engagement and LGBQ+ inclusion. In each model, a NSSE Engagement Indicator served as the outcome with the LGBQ+ inclusion variable as the independent variable of interest. We included students' major and sexual orientation as controls as well as a series of dummy variables for each institution to control for institution-level variance. We standardized variables before entry into models so that unstandardized coefficients can be interpreted as effect sizes. We ran models separately for LGBQ+ and non-LGBQ+ students.

To give context to these quantitative analyses, we also coded the open-ended survey responses where students shared "reflections or experiences regarding LGBQ+ issues" at their institution. We used an iterative process of inductive and deductive coding to analyze over 400 student written responses (Jones, Torres, \& Arminio, 2014). We used inductive coding to first identify emergent themes in the responses. We then compared and contrasted the emergent themes with our conceptual framework to organize the emergent codes and create new codes that had not organically emerged in the initial rounds of coding (e.g., course related experiences with LGBQ+ issues). We then used deductive coding to code the responses in the coding structure displayed in Figure 2. In the coding structure, " $n$ " is the number of students whose written responses we included in that code. We used qualitative results to give context to our quantitative

\footnotetext{
${ }^{4} d=.1$ is small, $d=.3$ is medium, $d=.5$ is large, and $d=.7$ is very large
} 
findings and provide insight on the lived experiences of students related to our research questions.

\section{Limitations}

Several aspects common to survey research limit this study. Institutions elect to participate in NSSE administrations, and students are not required to respond potentiality limiting our findings' generalizability. The questions and response options that NSSE provides additionally limit students' responses. Characteristics of identity, such as sexual identity, can be flexible and nuanced, making responses to static survey questions difficult. Additionally, in order to conduct statistical analyses, we had to aggregate students into groups. Although the distinction between groups can be meaningful, we recognize that the experiences of students within these groups is not monolithic and may likely hide the nuance of student experiences within these groups.

\section{Results}

To frame the study results, we present the findings in accordance with our two research questions:

1) How do perceptions of the curricular inclusion of LGBQ+ issues differ by students' sexual orientation and major?

2) How do perceptions of the curricular inclusion of $L G B Q+$ issues relate to other forms of engagement for both LGBQ+ and non-LGBQ+ students?

\section{How do perceptions of LGBQ+ inclusion differ by students' sexual orientation and major?}

Using t-tests, ANOVAs, and Cohen's d effect sizes, we examined differences on our LGBQ+ inclusion measure to see how these perceptions differ by students' sexual orientation (collapsed into an LGBQ+/non-LGBQ+ binary) and major or expected major. We ran all 
analyses separately for first years (FY) and seniors (SR), and we used Rocconi and Gonyea's (2018) recommendation for interpreting effect sizes using NSSE data. Students, both first year and senior, vary greatly in their perceptions of LGBQ+ inclusion by major $(p<.001)$ and sexual orientation $(p<.001)$. Students majoring in Arts \& Humanities $(\mathrm{FY}: \overline{\mathrm{x}}=29.4, \mathrm{SR}: \overline{\mathrm{x}}=31.3)$; Communications, Media, and Public Relations (FY: $\overline{\mathrm{x}}=29.2$, SR: $\overline{\mathrm{x}}=29.7$ ); Social Sciences $(\mathrm{FY}: \overline{\mathrm{x}}=26.3)$; and Social Service Professions (SR: $\overline{\mathrm{x}}=29.6)$ had the highest perceptions of LGBQ+ inclusion. Students majoring in Engineering (FY: $\overline{\mathrm{x}}=18.5, \mathrm{SR}: \overline{\mathrm{x}}=17.1)$; Health Professions (FY: $\overline{\mathrm{x}}=20.0$ ); Business (SR: $\overline{\mathrm{x}}=19.8$ ); and Physical Sciences, Mathematics, and Computer Science (FY: $\overline{\mathrm{X}}=20.3$, SR: $\overline{\mathrm{x}}=20.8$ ) had the lowest perceptions of LGBQ+ inclusion. The practical difference between the highest and lowest of these averages is quite large (FY: $d=$ .92$, SR: $d=1.13)$. Overall, LGBQ+ students perceive greater LGBQ+ inclusion than nonLGBQ+ students (FY: $d=.72, \mathrm{SR}: d=.74, p<.001)$.

In examining students' written responses, we focused on students who identified as LGBQ+ and the results illustrate that although some students had clear perceptions of their institutions as having a generally exclusive or inclusive environment for LGBQ+ students, it was more common for students to have a more nuanced perception of campus culture and climate. Campus inclusivity is not monolithic; many students reported areas of campus where they feel connected and supported (e.g., diversity or support centers, Pride or other LGBTQ+ centers/clubs, specific departments on campus) and areas where they have felt excluded or disconnected (e.g. specific departments or courses, sports teams and events, fraternities, sororities or other student organizations). These insights thus resemble Vaccaro's (2012) discussion on microclimates that individuals experience on campuses. When discussing the inclusion of LGBQ+ issues in curriculum, we observed stark differences by major. Students in 
social sciences, humanities and arts majors talked more about intersecting identities and the ways that their choice of study relates to LGBQ+ issues as discussed by a student who identified as a queer student ${ }^{5}$ :

Largely, aside from the typical prejudice and microaggressions that accompany navigating heteronormative spaces as a queer person, I would say there's a lack of representation and intersectionality of LGBQ+ issues and history across all courses I have taken... There's very little mention about non-heterosexual relationships unless you're taking a Sociology, Gender and Woman Science, or some psychology courses. Most of what I hear about LGBQ+ communities and stories I hear from my peers or from the Gender and Sexuality Center when they speak at events/meetings/conferences. I wish there would have been a greater inclusion and representation of LGBQ+ voices in my education.

Students in STEM and business majors expressed more educational disconnect with LGBQ+ issues and stated that they did not feel like these issues should be connected to their curriculum. An example of this educational disconnect was expressed by a student identifying as questioning:

I'm only taking upper level biology courses...LGBQ+ topics rarely pop up in class because of this. On the few ocasions [sic] these topics have come up during class (not as part of the lecture, but while talking before/after class or during breaks), they were discussed respectfully.

\footnotetext{
${ }^{5}$ In presenting quotes from students, we include the sexual orientation that they reported in the survey though we recognize that students have many other intersecting identities affecting their experiences.
} 
Similarly, another student who identified as bisexual notes: "Mostly LGBQ+ issues don't get brought up, but when they do, it's always with language and tone that suggests the professor is assuming none of the students in the class is on the LGBQ+ spectrum. It's uncomfortable and isolating, but bearable enough." Comments such as these serve to bring to life how students who identify as LGBQ+ experience the inclusion of LGBQ+ issues in the classroom.

\section{How do perceptions of LGBQ+ inclusion relate to other forms of effective educational practice for both LGBQ+ and non-LGBQ+ students?}

We used a series of regression equations to look at the relationship between engagement and LGBQ+ inclusion. In each model, a NSSE Engagement Indicator served as the outcome with the LGBQ+ inclusion variable as the independent variable of interest. We included students' major and sexual orientation as controls as well as a series of dummy variables for each institution to control for institution-level variance. We standardized variables before entry into models so that unstandardized coefficients can be interpreted as effect sizes. We ran models separately for LGBQ+ and non-LGBQ+ students.

We find all relationships between the various aspects of engagement and LGBQ+ inclusion to be significant for both first-year and senior students, as well as LGBQ+ and nonLGBQ+ students. The strongest relationships are between LGBQ+ inclusion and reflective and integrative learning activities-we find medium-large relationships for LGBQ+ (FY: B $=.40$, $\mathrm{SR}: \mathrm{B}=.41, p<.001)$ and non-LGBQ+ $(\mathrm{FY}: \mathrm{B}=.37, \mathrm{SR}: \mathrm{B}=.39, p<.001)$ students. Another notably strong relationship exists between $\mathrm{LGBQ}+$ inclusion and students' perceived gains, for non-LGBQ+ students (FY: B $=.29, \mathrm{SR}: \mathrm{B}=.27, p<.001$ ) and particularly for LGBQ+ students (FY: $\mathrm{B}=.42$, SR: $\mathrm{B}=.32, p<.001)$. Although small-medium relationships exist between LGBQ+ inclusion and having discussions with diverse others (FY: $\mathrm{B}=.24$, SR: $\mathrm{B}=.27, p<$ 
.001) for LGBQ+ students, stronger relationships exist for non-LGBQ+ students (FY: B = .32,

SR: $\mathrm{B}=.32, p<.001)$. See more details about these and other relationships in Table 3.

The write-in responses also demonstrate the ways that inclusive environments on campus enable students to thrive or create safe spaces that are in turn necessary to engage academically and socially even within a more hostile campus or community. A student identifying as a lesbian described a supportive and active organization for LGBQ+ students, but also noted how that community can create a safe space for some students but not everyone:

I think that while we have a solid LGBTQ+ community here, it's almost like we exist as a bubble separate from the rest of the campus community. Likewise, LGBTQ+ people not actively in the community feel alienated because those two social worlds rarely intersect. This is something we, the exec board, tried to work on but most of our efforts didn't have the effect that we had hoped for.

Students reporting that they only feel engaged and supported in a "bubble" on campus means that the general campus climate and specifically in the environments in classes are not places where students are able to engage with others. A student identifying as gay emphasized that creating these safe spaces for LGBQ+ students can be a matter of life and death:

As an openly gay person on this campus, I have been accepted and welcomed in certain environments. However, I have been verbally and physically attacked for my sexual orientation on this campus. A majority of these attacks have been by students, some of them quite involved in campus leadership at the time. The Office of Diversity Affairs, GLBTQ+ services, and the music department have been safe havens for me over the course of my four years. If it wasn't for these departments, I probably wouldn't be here, either leaving for another institution or committing suicide for not feeling welcome. 
...Change is going to have to come from all levels, students, faculty, staff, alumni etc. and truly reaching out to students and listening to their experiences.

As these students demonstrate, fostering an inclusive environment is critical for creating a safe and engaging education for LGBQ+ students. Interpreting the student responses along with the regression results highlight the importance moving beyond creating safe spaces to foster inclusive environments in and out of class in order for students to engage with each other, participate in reflective and integrative learning activities, and experience increased gains academic and professional gains.

\section{Discussion and Implications}

This campus is very $L G B T Q+$ friendly. It was a pleasant surprise to come here and feel accepted after attending a high school that was not so accepting. It is refreshing to have faculty who are not only willing to discuss LGBTQ+ issues, but also incorporate them into their coursework and lectures. Having authority figures that don't regard the mere existence of $L G B T Q+$ people as taboo was such a welcome change. I love it here! -Queer identifying student

The results from this study contribute significantly to scholarship in numerous ways that are necessary to reimagine higher education. The findings highlighted that perceptions of LGBQ+ inclusion were higher for those within the LGBQ+ community than those who do not identify as such. On one hand, this result can signal a positive reality for LGBQ+ students, especially when we consider the research showing that a collegian's perception of their institutional actions can lead to more academic success (Garvey, Squire, et al., 2018). On the other hand, it may be that LGBQ+ individuals paid more attention to LGBQ+ inclusion. 
All my courses are STEM, so sexuality is not discussed. It has little to do with any part of my life, except for my sexual life, which is completely detached from my educational experience.

-Bisexual identifying student

Additionally, results revealed that those in fields such as engineering and business perceived less LGBQ+ inclusion, echoing previous studies finding that certain disciplines further identityneutral practices that do not attend to LGBQ+ collegians' social identities (see Linley \& Nguyen, 2015; Rankin et al., 2019).

Furthermore, the results that emerged in relation to the second research question highlight a meaningful pattern. When looking at other forms of engagement, LGBQ+ inclusion positively predicted these types of engagement for both first-year and senior students, as well as LGBQ+ and non-LGBQ+ students. Though this relationship for LGBQ+ students is unsurprising considering the literature on culturally relevant pedagogy (Ladson-Billings, 2006), the fact that these educational practices also emerge significant in relationship to LGBQ+ inclusion for nonLGBQ+ students is valuable for higher educational professionals to recognize. Not only do these findings emphasize arguments made by scholars to integrate LGBQ+ issues into their teaching (Brockenbrough, 2018; Guerrero et al., 2017), this study displays how this practice benefits students across sexualities. Therefore, these results contribute to a small body of research acknowledging the connection between inclusion of LGBQ+ issues in curricula and positive impacts on different student populations (Sevecke et al., 2015).

Very diverse and accepting school but many courses and professors tend to shy away from talking about LGBT topics or issues which makes it uncomfortable to bring these issues up. 
This research has significant implications for faculty and staff in higher education, informing practices on college campuses that contribute to the reimagining of the study of higher education. Specifically, the results serve as an important foundation for faculty members to integrate an attention to LGBQ+ issues in their curriculum. There are a number of ways that this can occur. First, faculty should be intentional in creating lessons that do not reinforce heteronormativity (e.g., only discussing heterosexual relationships in a lesson on love in a psychology course). Second, faculty members can engage in this practice by drawing attention to the background of authors/theorists cited in their syllabi and how one's identities may have informed their work. Third, faculty should also vary who is represented in the examples that are provided in class (i.e., not solely relying on heterosexual couples when conveying material). Taking these steps could allow LGBQ+ students to see themselves in course material while also potentially benefiting those who do not identify as part of the LGBQ+ community.

As seen in the quantitative findings, this is particularly important in STEM fields, but student written responses illustrate the perception of disconnection between these disciplines and discussion or assignments related to LGBQ+ issues. To learn how faculty members can do so, they can turn to one of the significant relationships that emerged with the key forms of engagement: that of reflective and integrative learning activities. In particular, most faculty are in a position to not only teach students the content relevant to the class but also how students are socialized to academic discipline. Faculty members can more explicitly draw attention to LGBQ+ communities by asking students to participate in reflection that ask them to consider how their educational background and identities might affect how they navigate the profession.

Finally, it is imperative to acknowledge the work that student affairs practitioners can do to further the inclusion of LGBQ+ issues within the classroom. To begin, student affairs 
practitioners are increasingly teaching classes relevant to first-year experiences, academic readiness, or diversity and inclusion topics. As a result, student affairs professionals can similarly take up the recommendations provided for faculty members above about how to integrate LGBQ+ realities into their curricula. Moreover, select professionals have the ability to influence the work that faculty do inside of the classroom whether it is through providing diversity and inclusion training to these individuals or by serving in student affairs roles within academic departments. These practitioners are well situated to work alongside faculty members to help them think about LGBQ+ integration into courses, in addition to having the agency to intentionally program about LGBQ+ issues that exist in a specific discipline.

This study also provides a foundation for future research focused on understanding and assessing the experiences of LGBQ+ students. Although not central to our study, very important implications for further consideration became clear in students' responses to the write-in question. This study focused on sexual orientation, and thus asked about identification as bisexual, gay, lesbian, queer, questioning, or another sexual orientation (with a place to write in their response). Several of the respondents wanted "A" for asexual to be explicitly included in the questions and suggested excluding " $\mathrm{A}$ " was symptomatic of feeling generally overlooked or excluded in discussion of queer identities. In the creation of the item asking for students' sexual orientation, pilot testing and feedback from experts in the field showed that students largely have misconceptions about the meaning of "asexual," conflating it with ideas about not having sex or not being sexually active. Because of this, NSSE staff did not include this as an explicit response option (respondents, however, can still write in such responses).Therefore, institutions should work to educate students on the meaning of current queer terminology, and survey researchers should continue working towards making inclusive survey items. 
In a separate section of the NSSE survey, students were asked about their gender identity in a question that included the option to express trans or non-binary identities, but the additional questions about campus climate and culture associated with sexual orientation only focused on sexual orientation (LGBQ+) and not gender identity. We recognize that this felt exclusive to students who strongly identify with the larger LGBTQA+ community and individuals expressed the impact of this in their write-in responses such as "the sheer fact that you left the "T" out of LGBTQ+ is part of the erasure that goes on of LGBTQ+ issues." In the creation of this item set, NSSE researchers were intentional in focusing on issues around sexual identity so as not to conflate the differing experiences associated with sexuality and gender. Regardless, this feedback informs future research and illustrates the importance of being intentional about inclusive language in the classroom as well as in survey questions.

\section{Conclusion}

With the imperative to create culturally engaging environments for students from all backgrounds, but particularly those who hold minoritized social identities, higher education institutional agents face the task of reexamining their practices and policies across campus to foster more inclusive climates. Knowing that scholarship showcases that students who identify as a member of the LGBQ+ community regularly encounter hostile and discriminatory environments at colleges and universities (Evans et al., 2017; Garvey et al., 2017; Greathouse et al., 2018; Woodford \& Kulick, 2015), this study provides a necessary look at one particular area that professionals should target in order to make valuable interventions relevant to campus climates and cultures. Results indicate that integrating LGBQ+ issues into the curriculum is a move that faculty members can make across disciplines and that can have a productive effect on all students, including those who do not identify as part of the LGBQ+ community. However, 
most importantly, being able to see oneself represented in their coursework could drastically shift the ways that LGBQ+ collegians perceive their institution's commitment to their learning and success. This paper began with a challenge from a queer identifying student to "step it up." To be there for LGBQ+ students requires an attention to centering their stories and lived realities across campus, including in the classroom. 


\section{References}

Ackelsberg, M., Hart, J., Miller, N. J., Queeny, K., \& Van Dyne, S. (2009). Faculty microclimate change at Smith College. In W. Brown-Glaude (Ed.), Doing diversity in higher education: Faculty leaders share challenges and strategies (pp. 83-102). New Brunswick, NJ: Rutgers University Press.

Aronson, B., \& Laughter, J. (2016). The theory and practice of culturally relevant education: A synthesis of research across content areas. Review of Educational Research, 86(1), 163206. doi: $10.3102 / 0034654315582066$

Astin, A. W. (1993). Diversity and multiculturalism on the campus. Change: The Magazine of Higher Learning, 25(2), 44-49. doi: 10.1080/00091383.1993.9940617

Bilimoria, D., \& Stewart, A. J. (2009). "Don't ask, don't tell”: The academic climate for lesbian, gay, bisexual, and transgender faculty in science and engineering. NWSA Journal, 21(2), $85-103$.

Blumenfeld, W. J., Weber, G. N., \& Rankin, S. (2016). In our own voice: Campus climate as a mediating factor in the persistence of LGBT students, faculty, and staff in higher education. In P. Chamness Miller \& E. Mikulec (Eds.), Queering classrooms: Personal narratives and educational practices to support LGBTQ youth in schools (pp. 187-212). Charlotte, NC: Information Age Publishing.

BrckaLorenz, A., Haeger, H., \& Priddie, C. (2019). An examination of inclusivity and support for diversity in STEM fields. Paper presented at the 2019 annual meeting of the American Educational Research Association, Toronto, Canada. 
Brockenbrough, E. (2016). Becoming queerly responsive: Culturally responsive pedagogy for Black and Latino urban queer youth. Urban Education, 51(2), 170-196. doi: $10.1177 / 0042085914549261$

Brown, K. (2006). The educational benefits of diversity: The unfinished journey from "mandate" in Brown to "choice" in Grutter and Comfort. Leadership and Policy in Schools, 5(4), 325-354. doi: 10.1080/15700760600968390

Brown, R., Clarke, B., Gortmaker, V., \& Robinson-Keilig, R. (2004). Assessing the campus climate for gay, lesbian, bisexual and transgender (LGBT) students using a multiple perspectives approach. Journal of College Student Development, 45(1), 8-26. doi: $10.1353 /$ csd.2004.0003

Cole, D. (2007). Do interracial interactions matter? An examination of student-faculty contact and intellectual self-concept. The Journal of Higher Education, 78(3), 249-281. doi: $10.1080 / 00221546.2007 .11772316$

Cole, D., \& Espinoza, A. (2008). Examining the academic success of Latino students in science technology engineering and mathematics (STEM) majors. Journal of College Student Development, 49(4), 285-300. doi: 10.1353/csd.0.0018

Evans, R., Nagoshi, J. L., Nagoshi, C., Wheeler, J., \& Henderson, J. (2017). Voices from the stories untold: Lesbian, gay, bisexual, trans, and queer college students' experiences with campus climate. Journal of Gay and Lesbian Social Services, 29(4), 426-444. doi: $10.1080 / 10538720.2018 .1378144$

Garvey, J. C., Mobley, S. D., Jr., Summerville, K. S., \& Moore, G. T. (2018). Queer and trans* students of color: Navigating identity disclosure and college contexts. The Journal of Higher Education, 90(1), 150-178. doi: 10.1080/00221546.2018.1449081 
Garvey, J. C., Sanders, L. A., \& Flint, M. A. (2017). Generational perceptions of campus climate among LGBTQ undergraduates. Journal of College Student Development, 58(6), 795817. doi: $10.1353 / \mathrm{csd} .2017 .0065$

Garvey, J. C., Squire, D. D., Stachler, B., \& Rankin, S. (2018). The impact of campus climate on queer-spectrum student academic success. Journal of LGBT Youth, 15(2), 89-105. doi: $10.1080 / 19361653.2018 .1429978$

Greathouse, M., BrckaLorenz, A., Hoban, M., Huesman, R., Rankin, S., \& Bara Stolzenberg, E. (2018). A meta-analysis of queer-spectrum and trans-spectrum student experiences at US Research universities. In K. M. Soria (Ed.), Evaluating campus climate at US research universities: Opportunities for diversity and inclusion (pp. 49-76). New York, NY: Palgrave Macmillan.

Guerrero, C., Shahnazarian, A., \& Brown, M. F. (2017). Queer(y)ing culture through professional learning communities: A reimagining of culturally relevant and responsive pedagogy. Penn GSE Perspectives on Urban Education. 13(2), 1-12.

Hughes, B. E. (2017). “Managing by not managing”: How gay engineering students manage sexual orientation identity. Journal of College Student Development, 58(3), 385-401.

Hughes, B. E. (2018). Coming out in STEM: Factors affecting retention of sexual minority STEM students. Science Advances. Advance online publication. doi: 10.1126/sciadv.aao6373

Jones, S. R., Torres, V., \& Arminio, J. (2014). Negotiating the complexities of qualitative research in higher education: Fundamental elements and issues (2nd ed.). New York, NY: Routledge. 
Ladson-Billings G. (2006). "Yes, but how do we do it?" Practicing culturally relevant pedagogy. In J. Landsman \& C. W. Lewis (Eds.), White teachers/diverse classrooms: Creating inclusive schools, building on students' diversity, and providing true educational equity (pp. 33-46). Sterling, VA: Stylus.

Linley, J. L., \& Nguyen, D. J. (2015). LGBTQ experiences in curricular contexts. In D.-L. Stewart, K. A. Renn, \& G. Blue Brazelton (Eds.), Gender and sexual diversity in U.S. higher education: Contexts and opportunities for LGBTQ college students (New Directions for Student Services, no. 152, pp. 41-53). San Francisco, CA: Jossey-Bass.

Marquez Kiyama, J., \& Rios-Aguilar, C. (2017). Funds of knowledge in higher education: Honoring students' cultural experiences and resources as strengths. New York, NY: Routledge.

Museus, S. D. (2014). The Culturally Engaging Campus Environments (CECE) Model: A new theory of college success among racially diverse student populations. In M. B. Paulsen (Ed.), Higher education: Handbook of theory and research (Vol. 29, pp. 189-227). New York, NY: Springer.

Museus, S. D., Yi, V., \& Saelua, N. (2018). How culturally engaging campus environments influence sense of belonging in college: An examination of differences between White students and students of color. Journal of Diversity in Higher Education, 11(4), 467-483. doi: $10.1037 /$ dhe0000069

Patridge, E. V., Barthelemy, R. S., \& Rankin, S. R. (2014). Factors impacting the academic climate for LGBQ STEM faculty. Journal of Women and Minorities in Science and Engineering, 20(1), 75-98. 
Pike, G. R., \& Kuh, G. D. (2006). Relationships among structural diversity, informal peer interactions and perceptions of the campus environment. The Review of Higher Education, 29(4), 425-450. doi: 10.1353/rhe.2006.0037

Pitcher, E. N., Camacho, T. P., Renn, K. A., \& Woodford, M. R. (2018). Affirming policies, programs, and supportive services: Using an organizational perspective to understand LGBTQ+ college student success. Journal of Diversity in Higher Education, 11(2), $117-$ 132. doi: $10.1037 /$ dhe 0000048

Rankin, S., Garvey, J. C., \& Duran, A. (2019). A retrospective of LGBT issues on US college campuses: 1990-2020. International Sociology, 34(4), 435-454. doi: $10.1177 / 0268580919851429$

Rocconi, L. M., \& Gonyea, R. M. (2018). Contextualizing effect sizes in the National Survey of Student Engagement: An empirical analysis. Research \& Practice in Assessment, 13, 2238.

Rhodes, C. M., \& Coda, J. (2017). It's not in the curriculum: Adult English language teachers and LGBQ topics. Adult Learning, 28(3), 99-106. doi: 10.1177/1045159517712483

Sevecke, J. R., Rhymer, K. N., Almazan, E. P., \& Jacob, S. (2015). Effects of interaction experiences and undergraduate coursework on attitudes toward gay and lesbian issues. Journal of Homosexuality, 62(6), 821-840. doi: 10.1080/00918369.2014.999493

Tinto, V. (2006). Research and practice of student retention: What next? Journal of College Student Retention: Research, Theory \& Practice, 8(1), 1-19. doi: 10.2190/4YNU-4TMB22DJ-AN4W

Tyson, M. (2019). Cultivating campus environments to support diverse student populations. In C. Akens, R. Wright-Mair, \& J. M. Stevenson (Eds.), College students and their 
environments: Understanding the role student affairs educators play in shaping campus environments (pp. 88-111). Springfield, IL: Charles C Thomas Publisher.

Vaccaro, A. (2012). Campus microclimates for LGBT faculty, staff, and students: An exploration of the intersections of social identity and campus roles. Journal of Student Affairs Research and Practice, 49(4), 429-446. doi: 10.1515/jsarp-2012-6473

Woodford, M. R., \& Kulick, A. (2015). Academic and social integration on campus among sexual minority students: The impacts of psychological and experiential campus climate. American Journal of Community Psychology, 55(1-2), 13-24.

Woodford, M. R., Kulick, A., \& Atteberry, B. (2015). Protective factors, campus climate, and health outcomes among sexual minority college students. Journal of Diversity in Higher Education, 8(2), 73-87. doi: 10.1037/a0038552

Woodford, M. R., Kulick, A., Garvey, J. C., Sinco, B. R., \& Hong, J. S. (2018). LGBTQ policies and resources on campus and the experiences and psychological well-being of sexual minority college students: Advancing research on structural inclusion. Psychology of Sexual Orientation and Gender Diversity, 5(4), 445-456.

Woodford, M. R., Kulick, A., Sinco, B. R., \& Hong, J. S. (2014). Contemporary heterosexism on campus and psychological distress among LGBQ students: The mediating role of selfacceptance. American Journal of Orthopsychiatry, 84(5), 519-529. doi:

\subsection{7/ort0000015}

Woodford, M. R., Weber, G., Nicolazzo, Z., Hunt, R., Kulick, A., Coleman, T., Coulombe, S., \& Renn, K. A. (2018). Depression and attempted suicide among LGBTQ college students: Fostering resilience to the effects of heterosexism and cisgenderism on campus. Journal of College Student Development, 59(4), 421-438. 
Figure 1. Nested Model for Diversity and Inclusion

\section{Supportive Campus Environment}

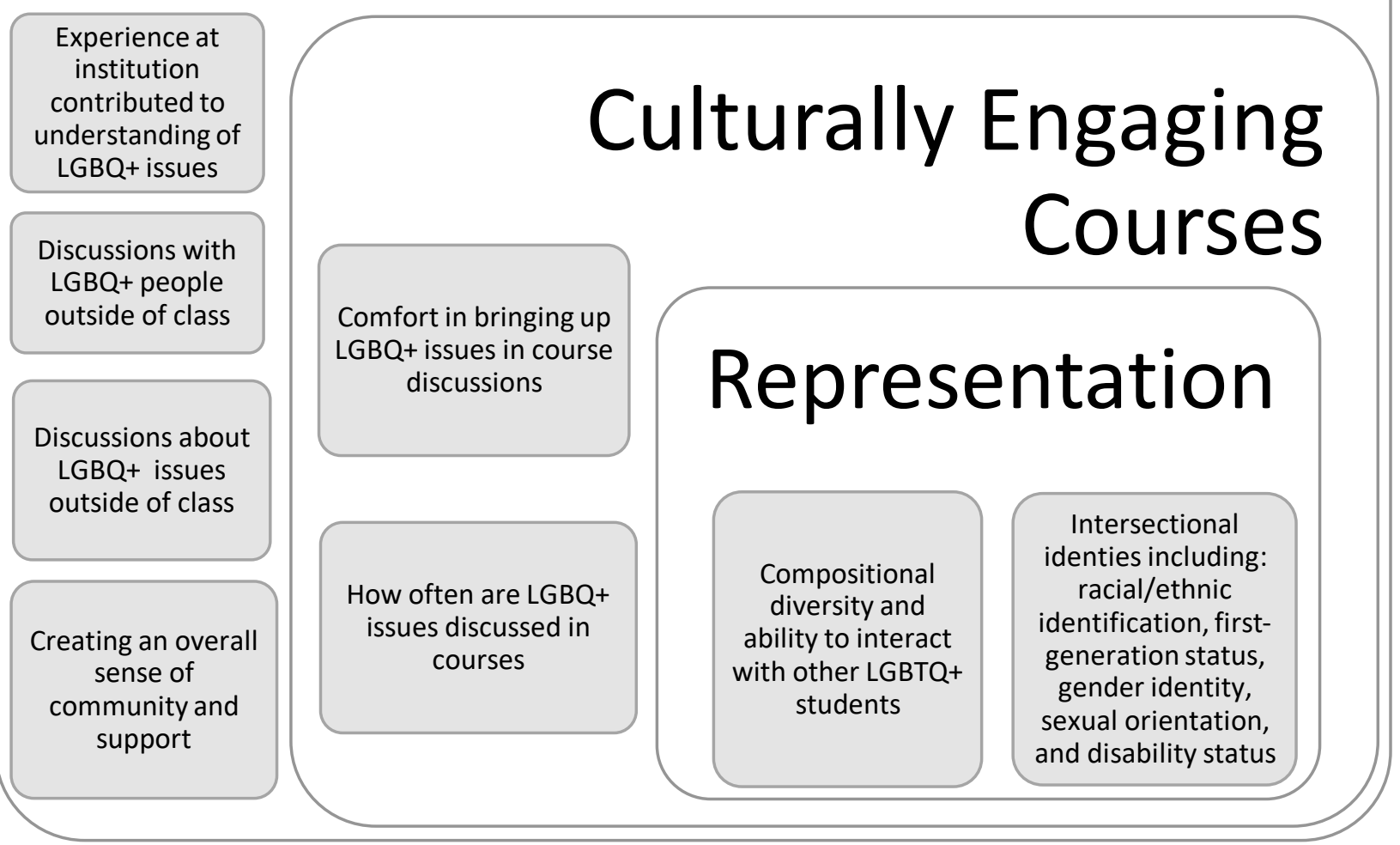


Table 1. Select Respondent and Institution Demographics and Characteristics

\begin{tabular}{|c|c|c|c|c|}
\hline & & First-year & Senior & Total \\
\hline \multirow{12}{*}{$\begin{array}{l}\text { Major or } \\
\text { expected } \\
\text { major }\end{array}$} & Arts \& Humanities & 14.6 & 12.5 & 13.4 \\
\hline & Bio Sci, Agric, \& Nat & 13.7 & 12.2 & 12.8 \\
\hline & Resources & & & \\
\hline & Physical Sciences, Math, \& CS & 7.8 & 7.0 & 7.4 \\
\hline & Social Sciences & 13.0 & 14.7 & 14.0 \\
\hline & Business & 16.5 & 17.6 & 17.1 \\
\hline & Comm, Media, \& PR & 4.6 & 4.5 & 4.5 \\
\hline & Education & 5.6 & 5.7 & 5.7 \\
\hline & Engineering & 7.9 & 8.1 & 8.0 \\
\hline & Health Professions & 10.7 & 8.8 & 9.6 \\
\hline & Social Service Professions & 3.1 & 3.7 & 3.4 \\
\hline & All Other & 2.4 & 5.1 & 4.0 \\
\hline \multirow{9}{*}{$\begin{array}{l}\text { Sexual } \\
\text { orientation }\end{array}$} & Asexual & $<1$ & $<1$ & $<1$ \\
\hline & Bisexual & 6.0 & 4.7 & 5.3 \\
\hline & Gay & 2.0 & 2.1 & 2.0 \\
\hline & Lesbian & 1.0 & 1.2 & 1.1 \\
\hline & Pansexual & $<1$ & $<1$ & $<1$ \\
\hline & Queer & 1.1 & 1.4 & 1.3 \\
\hline & Questioning or unsure & 1.9 & 1.3 & 1.5 \\
\hline & Straight & 86.4 & 88.3 & 87.5 \\
\hline & Another sexual orientation & $<1$ & $<1$ & $<1$ \\
\hline \multirow{8}{*}{$\begin{array}{l}\text { Basic } \\
\text { Carnegie } \\
\text { classification }\end{array}$} & Doctoral-Highest research & 13.6 & 16.6 & 15.3 \\
\hline & Doctoral-Higher research & 27.8 & 24.9 & 26.1 \\
\hline & Doctoral-Moderate research & 8.5 & 16.8 & 13.3 \\
\hline & Master's-Large programs & 10.8 & 13.2 & 12.2 \\
\hline & Master's -Medium programs & 2.1 & $<1$ & 1.2 \\
\hline & Master's -Small programs & 9.1 & 5.2 & 6.8 \\
\hline & Baccalaureate-Arts \& Sciences & 21.8 & 17.8 & 19.5 \\
\hline & Baccalaureate-Diverse fields & 6.3 & 5.1 & 5.6 \\
\hline \multirow{2}{*}{$\begin{array}{l}\text { Institutional } \\
\text { control }\end{array}$} & Public & 69.0 & 75.1 & 72.6 \\
\hline & Private & 31.0 & 24.9 & 27.4 \\
\hline \multirow{4}{*}{$\begin{array}{l}\text { Enrollment } \\
\text { size }\end{array}$} & Small $(1,000-2,500)$ & 21.7 & 16.5 & 18.7 \\
\hline & Medium $(2,500-4,999)$ & 15.5 & 13.2 & 14.2 \\
\hline & Large $(5,000-9,999)$ & 14.9 & 13.4 & 14.1 \\
\hline & Very Large $(10,000$ or more) & 48.0 & 56.9 & 53.1 \\
\hline \multirow{7}{*}{$\begin{array}{l}\text { Institution } \\
\text { region }\end{array}$} & New England & 4.0 & 3.4 & 3.7 \\
\hline & Mid East & 27.2 & 20.1 & 23.1 \\
\hline & Great Lakes & 40.5 & 34.9 & 37.3 \\
\hline & Plains & 5.1 & 5.3 & 5.2 \\
\hline & Southeast & 9.9 & 12.0 & 11.1 \\
\hline & Southwest & 8.6 & 11.9 & 10.5 \\
\hline & Far West & 4.7 & 12.4 & 9.1 \\
\hline
\end{tabular}


Table 2. LGBQ+ Inclusion Items and Measure Descriptions

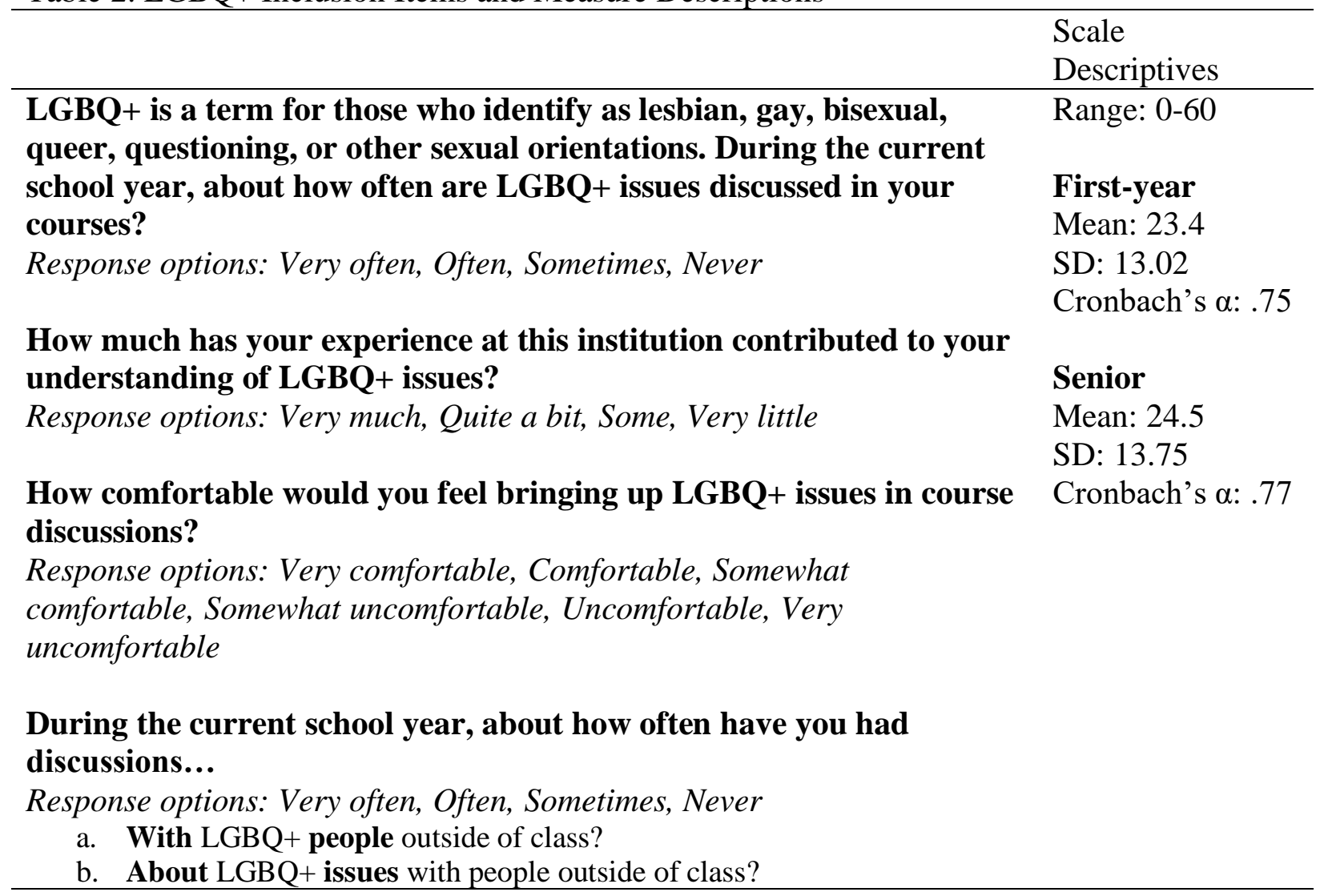


Figure 2. Coding Structure and Coding Density

\section{Campus Environment}

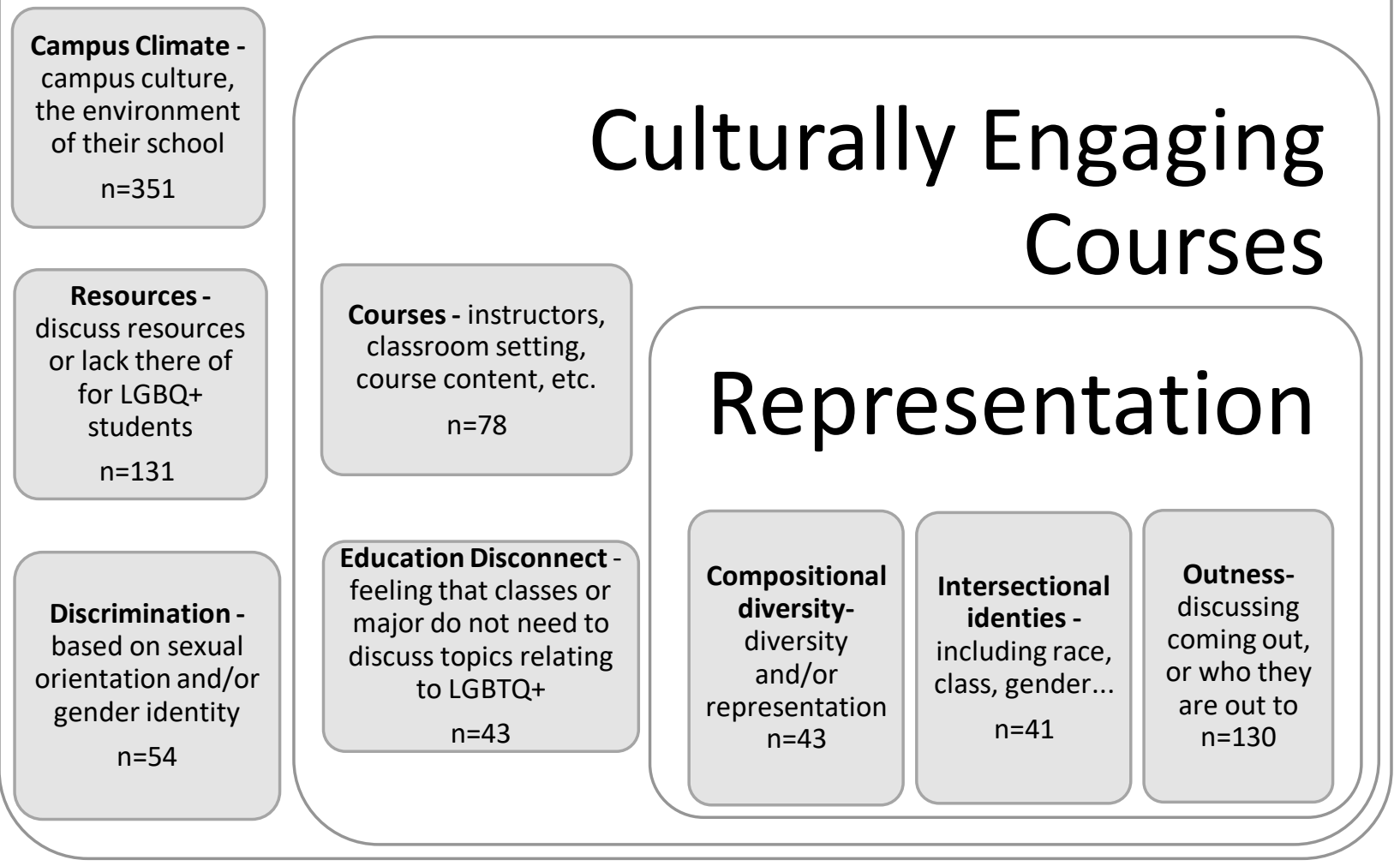


Table 3. Relationships between Engagement and LGBQ+ Inclusion by Class and Sexual Orientation

\begin{tabular}{lcccccccc}
\hline & \multicolumn{4}{c}{ LGBQ+ } & \multicolumn{4}{c}{ Non-LGBQ+ } \\
\cline { 2 - 9 } & \multicolumn{2}{c}{ First-year } & \multicolumn{2}{c}{ Senior } & \multicolumn{3}{c}{ First-year } & \multicolumn{2}{c}{ Senior } \\
\cline { 2 - 9 } & Unst. & \multicolumn{3}{c}{ Unst. } & \multicolumn{3}{c}{ Unst. } & Unst. \\
& B & Sig. & B & Sig. & B & Sig. & B & Sig. \\
\hline Higher-Order Learning & .30 & $* * *$ & .24 & $* * *$ & .21 & $* * *$ & .24 & $* * *$ \\
Reflective \& Integrative & .40 & $* * *$ & .41 & $* * *$ & .37 & $* * *$ & .39 & $* * *$ \\
Learning & & & & & & & & \\
Collaborative Learning & .21 & $* * *$ & .22 & $* * *$ & .20 & $* * *$ & .21 & $* * *$ \\
Discussions with Diverse Others & .24 & $* * *$ & .27 & $* * *$ & .32 & $* * *$ & .32 & $* * *$ \\
Student-Faculty Interaction & .23 & $* * *$ & .31 & $* * *$ & .24 & $* * *$ & .26 & $* * *$ \\
Quality of Interactions & .22 & $* * *$ & .22 & $* * *$ & .19 & $* * *$ & .15 & $* * *$ \\
Supportive Environment & .29 & $* * *$ & .26 & $* * *$ & .27 & $* * *$ & .25 & $* * *$ \\
Perceived Gains & .42 & $* * *$ & .32 & $* * *$ & .29 & $* * *$ & .27 & $* * *$ \\
\hline
\end{tabular}

$* * * p<.001$. We included students' major and sexual orientation as controls as well as a series of dummy variables for each institution to control for institution-level variance. We standardized variables before entry into models so that unstandardized coefficients can be interpreted as effect sizes. 